\title{
Perineal trauma as an existential change: a qualitative study with women experiencing humanized birth
}

\author{
Trauma perineal como mudança existencial: um estudo qualitativo com \\ mulheres vivenciando o parto humanizado
}

Raquel Bosquim Zavanella Vivancos ${ }^{1}$ (D), Aline Fernandes Pires Alem Almeida ${ }^{1}$ (D) Fabiana Villela Mamede $^{1}$ (i), Alessandra Cristina Marcolin ${ }^{(\mathbb{D}}$, Pedro Henrique Martins Valério ${ }^{1} \mathbb{D}^{(\mathbb{B}}$, Luiz Gustavo Oliveira Brito ${ }^{1}$ (D)

\begin{abstract}
Objective: To investigate how women experienced perineal trauma during a humanized birth.

Methods: A qualitative study with 22 postpartum women was performed from January to December 2018 . The Husserlian phenomenology was used as theoretical framework using individual, in-depth interviews that were audiotaped and transcribed verbatim.

Results: Twenty-four categories emerged from women's reports. During the prenatal phase, we found lack of information regarding perineal trauma, the alterity as a facilitating process to incentive women towards vaginal delivery and the perception of the beginning of an existential transition. During labor, it was noticed trust and attachment with the health professional giving physical and emotional support, the fear of the unknown linking to insecurity, the need for internal surrender to the process, empowerment as a result of trust and commitment, to give herself to the moment and no concerns with intrapartum injury but at the same time, having the possibility to share a decision-making process of suturing(or not). The postpartum period has shown the completion of the existential transition, the body as a place of estrangement, the loosening of some ties, but the construction of new networks of personal support to overcome postpartum.

Conclusions: Most of women after humanized birth perceived perineal trauma as an existential transition that was initiated during antenatal period.
\end{abstract}

Keywords: Humanized birth, Perineal trauma, Phenomenology, Midwife, Obstetrician, Alterity.

\section{RESUMO}

Objetivos: Investigar como as mulheres experienciaram o trauma perineal durante um parto humanizado.

Métodos: Um estudo qualitativo com 22 mulheres pós-parto foi realizado de janeiro a dezembro 2018. A fenomenologia Husserliana foi usada como referencial teórico usando entrevistas individuais que foram audiogravadas e transcritas verbatim.

Resultados: Vinte e quatro categorias emergiram durante os relatos. Durante o período pré-natal, a falta de informação sobre o trauma perineal, a alteridade como processo facilitador para incentivar as mulheres em direção ao parto vaginal e a percepção do começo de uma transição existencial. Durante o parto, a confiança e ligação com o(a) profissional de saúde com suporte físico e emocional, o medo do desconhecido e a insegurança, a necessidade de se entregar ao processo, o empoderamento como resultado de confiança e comprometimento, e o processo de tomada de decisão compartilhada da sutura (ou não). O período pós-parto mostra a completude da transição existencial, o corpo como local de estranhamento, o afrouxamento de alguns laços, mas a construção de novas redes de suporte pessoal para superar esse período.

Conclusão: A maior parte das mulheres depois do parto humanizado percebe o trauma perineal como uma transição existencial que fora iniciada durante o período antenatal.

Palavras-chave: Parto humanizado, Complicações do trabalho de parto, Pesquisa qualitativa, Obstetrícia..

1. University of São Paulo. Medical School. Department of Gynecology and Obstetrics, Ribeirão Preto, (SP) Brasil 


\section{INTRODUCTION}

Perineal trauma is a frequent situation during labor and presents a diverse prevalence worldwide ${ }^{1-3}$; however, this event may influence the development of several pelvic floor disorders (urinary incontinence, fecal incontinence, chronic pelvic pain) and the decision for having another birth in the future ${ }^{4}$. Severe perineal trauma, more commonly entitled obstetric and anal sphincter injuries (OASIS), occurs less than $5 \%$ of deliveries and may increase the prevalence of the pelvic floor disorders (PFDs) ${ }^{1}$.

Several risk factors are associated with severe perineal trauma: fetal macrosomia, instrumental delivery, prolonged second stage of labor, shoulder dystocia, nulliparity and Asian women ${ }^{4}$. There are some controversial risk factors (episiotomy, hands-on/off, birthing position in the second stage, waterbirth) that needs further clarification ${ }^{5-7}$. Some interventions present moderate quality of evidence that may reduce the risk for perineal trauma, such as antenatal perineal massage ${ }^{8}$, and the use of warm compresses during labor ${ }^{9}$. There are some active measures that can be performed to reduce the incidence of perineal trauma such as controlled progress of the baby's head, maternal position that allowed visualization of the perineum, selective episiotomy using lateral or mediolateral techniques ${ }^{10}$.

Perineal trauma may cause a sensation of guilt and impotence in health professionals that assist deliveries ${ }^{11}$. This reinforces the importance of increasing knowledge of the professionals involved in labor, competence or identification and referral to personnel capable of repairing the lesions. But for patients, the experience is also not enjoyable. A meta-ethnographic review published in 2014 about women's experiences following OASIS has found that there is some prejudice in physical and psychological outcomes, with some women experiencing social isolation and marginalization ${ }^{12}$. Furthermore, a more recent review about perineal trauma, regardless of severity, has shown the same results ${ }^{13}$. However, most of the qualitative studies have interviewed women that experienced vaginal deliveries in an environment that not always have taken into consideration their feelings, values, beliefs, emotions, dignity, and autonomy over their pregnancy and delivery, that is, they have not experienced a humanized birth ${ }^{14}$.
Do we know, in a humanized birth, whether woman's satisfaction with labor experience may influence her perception about diagnosis and repair of a perineal tear? To our knowledge, this question was not thoroughly answered. It is important to recognize how she perceived the lesion or her feelings after the diagnosis informed by a midwife or obstetrician and how this was managed. It is critical to understand what perineal trauma means for women and how these lesions may impact her well-being, her partner and family. It is also essential to understand how these lesions may influence woman 's decision to undergo another vaginal delivery in the future. Thus, we sought to investigate how women experienced perineal trauma during a humanized birth and how this connects with antenatal period, labor, and immediate postpartum period.

\section{METHODS}

This was a qualitative study performed from January to December 2018 in the city of Ribeirão Preto. The Institutional Review Board from Hospital das Clinicas da FMRP-USP has approved this study (CAAE 58847616.9.0000.5440) and all eligible women were included in the study if agreed to participate and signed the informed consent. All the steps of this study followed the COREQ (Consolidated criteria for reporting qualitative research) ${ }^{15}$.

The theoretical framework was the phenomenological approach, which does not add only a description of the experience, but also an interpretative process, in which the researcher interprets the meaning of the lived experiences. In this way, phenomenology provides a deep understanding of a phenomenon, as it is experienced by several individuals, to a universal description ${ }^{16}$.

Women were invited during postpartum period (at maximum one year after labor) by e-mail or telephone. Snowball sampling was another strategy, because women knew other women that would have underwent through the same experience. All deliveries were assisted by midwives and/or obstetricians attached to a humanized model of childbirth care with the following characteristics: respect to a programmed birth plan worksheet, care to avoid unnecessary interventions and provided by a multidisciplinary team (including a doula during all labor period) and access to non-pharmacological and pharmacological resources for pain relief. Exclusion criteria were women with no perineal trauma during labor and women that underwent instrumental deliveries. 
A pilot study was composed of three patients, in which the interview script was tested and the interviewer (A.L.P.A.A) was supervised by an observer (R.B.Z.V) to assess whether she was prepared to the task.

The interview was performed at woman's own home, except for one case, which was undertaken at the participant's office address at her request. All interviews were scheduled at woman's preferred time in order to control all external factors (eg. noise, other people) that might impair the women's responses. Duration of the interview ranged from 20 to 75 minutes and it was audio recorded and transcribed verbatim.

Despite a saturation criterion was attempted to reach, this concept is debatable in the phenomenological approach, since the goal of the study is to achieve something next to internal validity on quantitative research.

This step was guided by a four-stage phenomenological approach: 1 - data immersion, 2 - content reduction, 3 - organization and transformation of data (meaning units) and 4 expressing of the constituents of the phenomenon. Transcripts were extensively re-read with repeated listening of the audio to facilitate immersion in the data (R.B.Z.V). The key constituents were supported by direct quotations from interviews. After step number 3, the first author discussed with other co-authors and the senior author to confirm the preliminary findings and consensus was reached around the final results, bolstering the data shown from this study. All sentences from the interviews were de-identified, and patients were represented by a number (order of the interview).

\section{RESULTS}

\section{Patient characteristics}

A total of 20 patients were interviewed. Mean maternal age was 33.6 years. Almost all patients $(n=19)$ presented more than 12 years of education and half of them were health professionals (eg. dentist, physical therapist, pharmaceutics, physician, psychologist, nurse, and nutritionist). All patients were heterosexual and had a partner. All of them were accompanied by their partners throughout the labor and delivery. Regarding parity, 12 were primiparous, three women presented a previous vaginal delivery and five had a previous cesarean section. Mean pregnancy duration was 39 weeks and 5 days; mean number of prenatal consultations were 11 and most of women $(n=15)$ received a specific preparation for humanized vaginal delivery by doulas and midwives. Most patients practiced physical activity during gestation; yoga was the most prevalent activity $(n=6)$. All participants had their deliveries assisted by an obstetrician; nineteen women were also assisted by a midwife and 9 had a doula throughout the period. The interviews occurred between 40 and 180 days after birth.

\section{Emerging themes from the phenomenological analysis}

Three major axes were built from the three moments (pregnancy, labor and postpartum) that women experienced to having birth and the relationship with the meaning acquired from having perineal trauma. These axes were distributed into subthemes (Figure 1) and most categories emerged from the labor period.

Subthemes related to pregnancy (Table 1)

\section{A new relationship stablished with herself - the beginning of the existential transition}

The way the pregnant woman perceives herself in the face of so many transformations, demands, acceptance and resilience when facing the loss of an established routine, when perceiving a change from the common place for the occupation of another, may generate insecurity. A look at the subjectivity of this space of experiences points out to the feeling of loss of personal references - woman may feel that she is giving up from oneself to accomplish an existential project. This space of experience, also called "existential transition", has its beginning already during gestation. It can be positively or negatively influenced by relations of alterity established during the process, which may or may not provide enough resources to face the physical, psychosocial, and existential challenges from being pregnant, giving birth and living in the "motherland". 

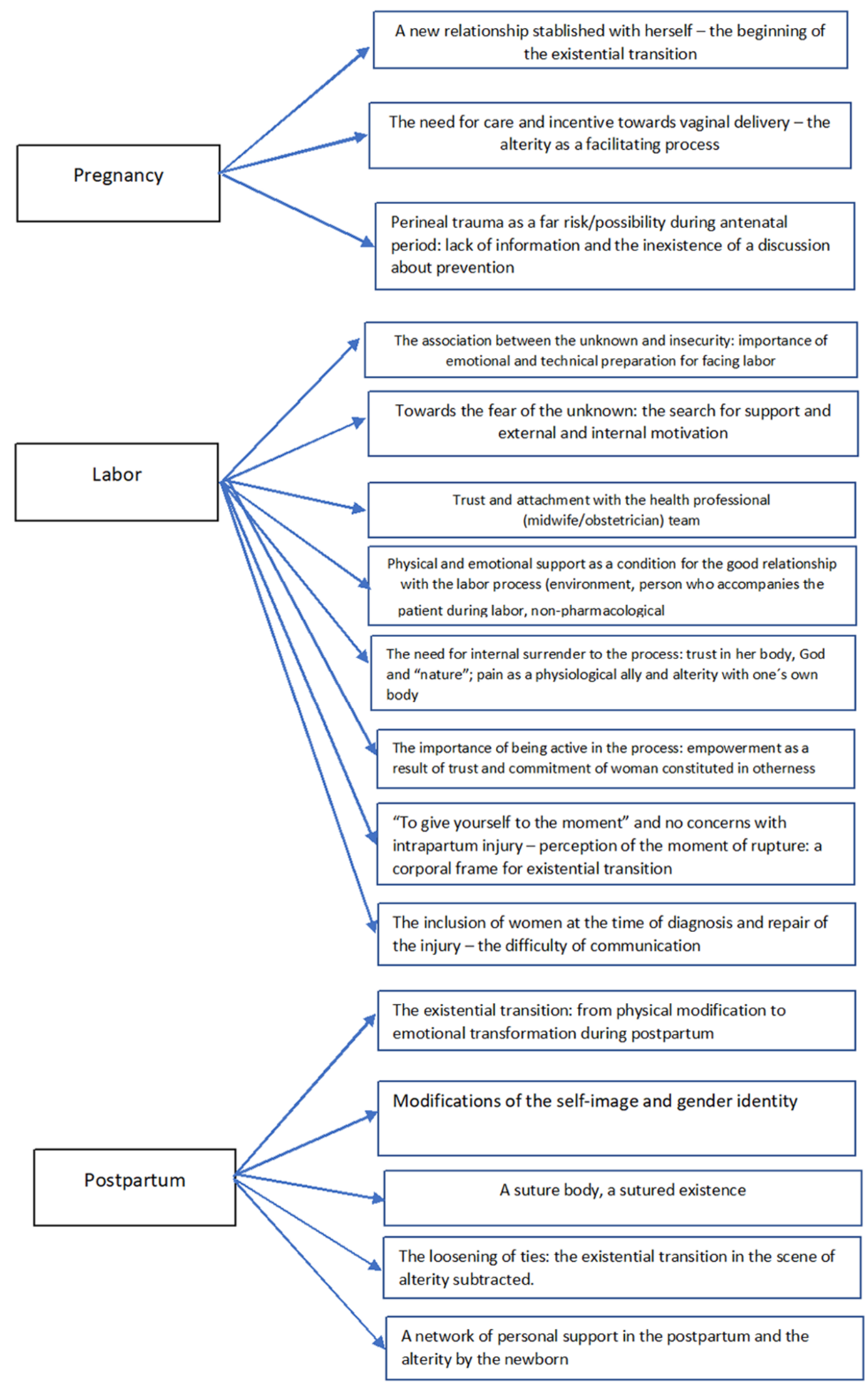

Figure 1. Themes and subthemes emerged from the phenomenological approach 
Table 1. Transcripts from subthemes related to pregnancy.

Categories
A new relationship
stablished with herself
- the beginning of the
existential transition

The need for care and incentive towards vaginal delivery - the alterity as a facilitating process

\section{Perineal trauma as a far risk/possibility during antenatal period: lack of information and the lack of a discussion about prevention}

\section{Transcripts}

"The whole experience of gestation? Oh, I did not think it was good ... I had six months of nausea, you know? So, this made everything less pleasant ... then there is a phase that makes us not easygoing. It impaired my development at my job because I was very sleepy ... And it seems that the brain is impaired as well, it makes us to do a lot of bullshit [...] I made some mistakes at work that I did not like. So, I did not see any glamour in being pregnant" (P12)

"The whole experience of gestation? Oh, I did not think it was good ... I had six months of nausea, you know? So, this made everything less pleasant ... then there is a phase that makes us not easygoing. It impaired my development at my job because I was very sleepy ... And it seems that the brain is impaired as well, it makes us to do a lot of bullshit [...] I made some mistakes at work that I did not like. So, I did not see any glamour in being pregnant" (P12)

"I was very happy in my pregnancy ... I even joked that if I would have about 10 children if it was because of being pregnant... (laughs). And I was not even expecting to get pregnant, huh? I was taken by surprise, but it was a very welcome surprise. And my pregnancy, I was blessed ... I did not have nausea, I had a lot of liveliness in my gestation ... a lot of other pregnant women said: "Oh, my head got bad, I was very emotional, ... "I was emotional too, but it was not a negative emotion, it did not prostrate me, it did not paralyze me ... On the contrary, it was a wonderful phase. I was feeling more beautiful, very active. My head - I work as a teacher - in the classroom, I was super connected with the ideas, intellectually I was very stimulated in the gestation. I do not know what happened, but something worked well... maybe the hormones worked out right there ..." (P19)

I think during pregnancy what I experienced as bad, let's put it like that, it was literally the feeling that I was going against the system, the whole time. I presented a health insurance, but in order to fulfill the dream of a vaginal delivery, I had to pay for a non-insured physician. This was disappointing for me, because almost all physicians I've sought through the plan encouraged me to have a cesarean section. When I was at the 35th week, the physician I was consulting said that the baby was still pelvic, so it would be better to schedule the elective cesarean section. So, I think this was a bit scary. If I did not have so much information, if I did not seek for it, I would have ended up doing an unnecessary cesarean, for no reasons ... a scheduled cesarean... I understood that the baby was at a breech presentation, but I did not want to undergo a scheduled cesarean (P1).

[...] I actually remember that the nurse told me [...] she talked to me, that I would have to do exercises for strengthening my vagina. But I was already tired, you know when you do not ... I did not think much of it. Since we do not know how it's going to be, I do not think I took it too seriously, to say, "Oh, I need to do it, I need to think about some exercises to do." I went to think about it later. I did not worry about that before (P2).

[...] I would do differently in order to prepare myself more for this, because I think I cared a lot about the time of childbirth, about the humanized issue, about how it would come to the world, that I wanted it to be a normal birth, not a C-section... and I did not worry about the perineum, to prepare myself about what was yet to come" (P9)

Uh, I remember I questioned ... I questioned it too, not that I was informed. I questioned this to my doctor, and I remember she said that the question of urinary incontinence, it can occur even in a cesarean section [...], let's suppose, was more the weight of the fetus in the bladder and not necessarily during pushing time. So that was more or less what she explained to me and then I was calmer ... but I questioned, I am the one who addressed this matter in one of the prenatal consultations (P7).

[...] was very important, I liked it a lot. I liked to feel, to know that there was this muscle inside me that I did not even know I had this ... we do not even have much conscience ... And to have contact with the pain ... Because the exercises are very painful, very! I even stopped going there because I was getting really scared of the pain of the exercise. [...] I was becoming very frightened if I would handle it and I ended up interrupting the physiotherapy exercises so that I did not feel that much suffering. However, you know that I started to push during labor, and I began to feel the pain in my vagina, the burning, it was not a scary thing, because I had had contact before. So, I thought it was very valid to train these exercises so that I could become familiar to what would happen to me. (P6) 
The need for care and incentive towards vaginal delivery - the alterity as a facilitating process

The current movement against the high rates of elective cesarean sections accomplished by civil society - mostly women - and the "islands" of professionals and services aimed at providing safe and humanized normal birth in the country can be great allies in the context of high maternal and infant mortality rates as consequence of the poor quality of obstetric care offered. The study participants showed that the pathway towards vaginal delivery could not be traversed without efficient professional support, such as: technical safety, evidence-based recommendations, active listening, sensitivity, and acceptance by the team.

The alterity in the professional assistance was shown to be a facilitating agent for vaginal delivery in the study. Teamwork characteristics were determinant for the woman to be able to perform the humanized vaginal delivery, in a care setting where most of women make the decision for undergo cesarean section, mainly due to fear of vaginal delivery.

Perineal trauma as a far risk/possibility during antenatal period: lack of information and the lack of a discussion about prevention

Most of women $(n=13)$ reported having received perineal preparation for delivery (perineal massage or vaginal dilators, such as Epi-No). Only four participants reported a prenatal consultation with a physical therapist. However, women referred that they did not know that preparation could be a prevention for OASIS. Most of participants said they knew that perineal trauma could happen, but they received "superficial and scant" information. Nevertheless, some women said it was good to feel strengthening their pelvic muscles.

\section{Subthemes related to labor (Table 2)}

\section{The association between the unknown and} insecurity: importance of emotional and technical preparation for facing labor

The relationship between the unknown and the insecurity is well established in the trajectory for childbirth. It was observed through the reports that the more the woman became aware of how the process would proceed, including the possibility of the perineal lesion, the better she administered anxiety and insecurity, favoring a relationship of trust with herself and the team.

Towards the fear of the unknown: the search for support and external and internal motivation

The search for sources of strength within alterity, whether with herself or the others, explain this category during the analyses of women's report (Table 2).

\section{Trust and attachment to the health professional (midwife/obstetrician) team}

The studied women have stablished with the team a sustained attachment based on trust and self-respect. They felt alive and perceived themselves as part of the whole process. In a phenomenological analysis they have manifested a physical and satisfactory experience. It is possible that, by these correlations, these relationships based on trust and positive reinforcement may create an interior space of self-support that empowers women towards the challenges that will be experience during pregnancy and postpartum period.

Physical and emotional support as a condition for the good relationship with the labor process

The use of non-pharmacological resources for comfort and pain relief during labor are connected with the bond and physical presence of someone throughout the process. The alterity presents in the doula, companion and teamwork are a condition that became resources against pain more effectives.

The need for internal surrender to the process: trust in her body, God and "nature"; pain as a physiological ally and alterity with one's own body

Giving birth have implied a physical and mental surrender basically structured by the force and trust acquired by the women, in the other and 
Table 2. Transcripts from subthemes related to labor.

\section{Categories}

The association between the unknown and insecurity: importance of emotional and technical preparation for facing labor

Towards the fear of the unknown: the search for support and external and internal motivation

Trust and attachment to the health professional (midwife/obstetrician) team

Physical and emotional support as a condition for the good relationship with the labor process (environment, person who accompanies the patient during labor, non-pharmacological resources for pain relief).

The need for internal surrender to the process: trust in her body, God and "nature"; pain as a physiological ally and alterity with one's own body

The importance of being active in the process: empowerment as a result of trust and commitment of woman constituted in the alterity

\section{Transcripts}

I have never worried about the injury ... because I do not know if I had confidence that maybe it would not happen ... or, if it happened too, I would face it in a natural way ... I knew that to pass the baby, it could happen ... so I was prepared for it, I was not worried ... I did not even think about it... I did not have that kind of concern (P1).

"...and I do not have my mother anymore ... so I said to myself: "how will I deal with the greatest pain in the world without having the greatest strength in the world, which was my mother to me?" [...] and to the extent that these fears also came, the more I gave myself to the moment... it was a process of total surrender" (P19)

"I can say that I felt really empowered, very strong ... it was a very

big transformation in my life ... I had an expectation that it would be difficult, it would be a difficult transforming moment."(P17)

[...] funny, right? But I did not even think about the possibility ... to be nervous, ... I think I was surrounded by so many people there, that I knew what I was doing, that I just let myself be guided ...(P1)

"I do not remember exactly the position, but it was kind of on the four, down on my knee in the bed and I threw my body on the pillows, the pillows ... and my husband pressed my hips at the time of contraction. I do not remember exactly the position, but I remember that this pressure of the hip absurdly relieved the pain, the contractions"(P3)

For me the greatest relief from the pain was in the ball and in the shower. In fact, the whole set of the work ... which, sitting on the ball, the nurse did enough massage on my back, the smell, the music, the calmness of her ... So, all this was very interesting. The freedom she gave me to: "Do you want to get out of there? Want to try something else? Want to try going to the shower? Do you want to stay here? Do you want to lie down? Do you want this? "So, this ... several people ask me," Oh and the pain, is it unbearable? "No. I remember, it's actually a strong pain, yes, but it was not a business that ... I remember sitting on the ball and sitting on the stool in the shower, trying to relieve myself, and the time I remember it I do not feel pain ... I do not suffer. (P8)

"I thought that, no matter what happens, I believe in the nature of my body, I imagined that it would not be a pain that I couldn 't bear, and that my body would handle this moment" (P19)

"In the beginning, I started to felt and then I realized that I had to try to find my labor position, to relax as much as I could, and to be on control...in my own control...maybe I would not be on control when the contractions came but I could control how I faced the contraction"(P22)

I felt very human, very woman ... very satisfied! It would not do any different. I try to talk to other mothers who are going to have it and take away that prejudice that has it. I think ... I felt ... looking at it all, after I caught my son on my lap, I saw the place I had ... I felt a sense of "That's the natural! This is what would have to happen, it's the ideal! "Because I did not need much ... and it was not something ... a negative experience ... of course there are cases and cases, but there for me, I ... what I had there, I did not need anything else for him to be born. And after I put it on my chest, I saw how he sucked ... it was all very spontaneous, everything very fast, it already sucked ... so to me that was very satisfactory, to have that result so immediate (P14).

As soon as I discovered her gestation, this was my main focus: "I have to actively prepare myself for this ... not only read, but it is talking with professionals, knowing my body, reading about positions ... "so I felt that I was very passive in the gestation and the last childbirth, and in that I wanted to be much more active .. that was decisive ... and this time I felt much more active, much safer of what was happening (P22). 
"To give yourself to the moment" and no concerns with intrapartum injury perception of the moment of rupture: a corporal frame for existential transition

The difficulty of communication at the time of diagnosis and repair of the injury
"During labor, you surrender ... so then, especially in the end, you do not ... it does not matter anymore... no matter if you poop, if you pee ... you become an Indian. You get totally naked, let's say ... if you need to walk naked in the hospital, you walk ... you really get like this ...(P17)

"Because during labor you do not worry about anything ... your head is .... there is no body, there is ... only your surrender" (P22)

"....it was a paradox even because at the time I realized that I felt pain during the laceration (I assumed that), I felt a relief that the baby came out...at the same time....so I felt it rip perfectly, it's a visceral rip with burning, followed by a fire ... hot, hot, hot, hot ... but the relief was so great that the baby left ... it's very interesting ... the pain is minimized ... I also imagine that we have many hormones in this process that help." (P19)

So, at the time we are so tired that I do not remember, honestly, if ... he said: "Look, it ripped ... I do not remember ... I think the focus was on something else and then, after I was with her a little in the my arms, that cut the umbilical cord, everything ... then he put me down there and said that he would need to give some stitches, while she weighed and everything else (P9)

Oh, I'm going to have to put some stitches here, ok? I will apply the anesthesia to give the 3 stitches or you prefer that I do not make the suture? Because for many times it recovers by itself... But I think if I do, the healing will be better ... "and what else did he say? There was one more thing ... "It will be better to heal the area and I said "no, you can do the stitches then" then he applied the anesthesia, gave the stitches ... and it was all done.

At the time the nurse and the doctor said, "Come on, it must have ripped." So, when I lied in bed, they already looked at each other and said, "So...we're going to give you a few stitches, it's normal ... "But they did not talk about how big it was the laceration ..." they just said it lacerated, so we'll give a few stitches to stop bleeding. "And then when we went to the operating room and there, I said to them "Guys, did the tear was big? Why haven't you stopped sewing things down there? "Then she said:" It's because you had several microtears around your vagina, I do not know why. But do not worry, it's all right. "(P19) sometimes, in "something bigger". The possibility of having the control and "listening" to their own body were only possible because the teamwork respected women's autonomy, and this involved empathy and it self-revealed through alterity.

\section{The importance of being active in the process: empowerment as a result of trust and commitment of woman constituted in the alterity}

Empowerment is based in an a intimal, personal, even spiritual trust, that "everything is going to be fine". The active role from these women during intrapartum period has surpassed the movement and can be translated as "let it go". This moment had the dimension of faith and self-trust, measured by the alterity on herself and attached by the bond and trust in the other. Lastly, positive reinforcement strengthened women, so she allowed to "be guided". It is implicit that many times is reinforced the difficulty for facing labor, because there are no motivation and drive constructed in the routine women environment.

\section{"To give yourself to the moment" and no concerns with intrapartum injury - perception of the moment of rupture: a corporal frame for existential transition}

During the reports, the "surrender preceded the moment of existential transition from women 
to being mother, physically materialized by the rupture of the perineum during fetal expulsion. In this moment, the lack of control and concern with the perineum reported by women may be influenced by chemical or emotional factors related to the expectation towards the encounter with the baby and the trust acquired in her own body.

\section{The difficulty of communication at the time of diagnosis and repair of the injury}

After reading the reports, it became noticeable the difficulty of communication about the diagnosis and repair of the perineum lesion by the health professional - this was very connected with the physical and emotional woman's state. Furthermore, it was frequent the attempt by the professional to reduce the magnitude of the perineal tear, using diminutives for lots of words while trying to tell the patient about the lesion. This can signify that not talking about perineal tears during antenatal period may be secondary to the myth that this should not happen during labor. Some women also reported that there was shared decision-making process with their professionals about suturing or not the $1^{\text {st }}$ or $2^{\text {nd }}$ degree perineal tear.

\section{Themes related to postpartum (Table 3)}

\section{The existential transition: from physical modification to emotional transformation during postpartum}

The process of existential transition is hallmarked by labor and perineal lesion. It seemed to occur by an attitude of surrender, trust and interior strength that turns into frustration during postpartum period. The alterity seems to be subtracted in this period. The impotence and the fear of not returning to their body before pregnancy is a characteristic of this period.

\section{Modifications of the self-image and gender identity}

Women reported they did not feel that they were the same, and this had led to a self-reflection regarding themselves, to a modified vision of being a woman. It is noted from each report that each woman will deal with these unfoldings with different approaches, individual resources and a technical and social network.

\section{A suture body, a sutured existence}

In the postpartum, woman closely relates to her body and her existence, more specifically with the sensation and pain caused by perineal trauma and modifications of the pelvic floor. The sutured body transposes the physical barriers, leading the women to a condition of a sutured existence. Some women presented pelvic pain, urinary incontinence, and need help from others to cope with the healing process.

\section{The loosening of ties: the existential transition in the scene of alterity subtracted.}

The possibility of a connection between the health professional and patient during prenatal care may not persist in the postpartum period and this points out to the traditional mode of care that needs reflection, because this happens even in a population with good health assistance. Even with the lack of specific information about the pelvic floor and its alterations in the puerperium, antenatal care that presuppose active listening and empathy should be enhanced. The perception that care is different before, during and after delivery is clear to some women. The impotence for postpartum woman is perceived in the analysis of the reports as a sedative. Her discourse is not valued or potentiated in all its magnitude.

\section{A network of personal support in the postpartum and the alterity by the newborn}

Women with higher level of physical and emotional resilience perceived that they have experienced lesions of lesser extent and clinical importance, but they have reacted accordingly. Furthermore, having a child has proved to be an important reference point in the reconstruction of the identity of being female by becoming a mother. The focus on the newborn during the immediate and late postpartum demonstrates the need for a relationship, which has enabled resilience and physical/emotional shelter for these women in the face of challenges and difficulties. 
Table 3. Transcripts from subthemes related to postpartum.

\section{Categories}

The existential transition: from physical modification to emotional transformation during postpartum

Modifications of the self-image and gender identity

A suture body, a sutured existence

The loosening of ties: the existential transition in the scene of alterity subtracted

A network of personal support in the postpartum and the alterity by the newborn

\section{Transcripts}

"Ah, emotionally it's a bit difficult for us at the beginning, because we feel ... It's a very difficult period, because there's the baby to take care of, you're bleeding, you have the vaginal tear to heal, you have to breastfeed ... all of this is awful. The pain of postpartum is a sentimental pain ... because you're tired, you're ... it's difficult for people to understand ... You cannot actually say to the people you're surrounded by what you're feeling ... I felt it so ... hurt sentimentally, you know? I say the postpartum pain was worse. I felt a very large emotional pain, a very large void. It is a pain that I cannot explain, a feeling of loss, loss of oneself, to meet again with our own body (P17)

It really feels like you're not in the same (body) ... You feel dirty, as if you were mistreated. Bad hair, bad skin, you're going to take a shower, but it looks like you did not... It feels a very strange sensation ... It feels bad ... It's not an easy sensation ...I did not have a cesarean, the same day I got out of bed, I took a shower ... I did not need care, but even though, I had a feeling of sadness (P17).

[...],I think that my vagina, my perineum - it's not the same, I had a suture on my labia, and it became with another format. So that's crazy, because you do not identify your own vagina ... You look and say, "Jesus, it's from somebody else!" But it was not a change that undermined my physiological functions. Initially, I was very angry ... I said: "Guys, why didn't you let me know you're going to do this? Like ... ", I was a bit shocked, but then the pain passed and then I saw that it was not a negative change either, so I was fine later them. (P19)

Yes, it was a very big limitation, I felt ... I think two stitches fell off ... I had difficulty to sit down... I had this idea that vaginal delivery would be with no difficulties and it would be a lot better, right? But I had a physical limitation due to the stitches... I stayed for several days with a lot of pain to sit down...

I was very insecure even to clean my vagina after I pee, so it was very uncomfortable, a lot. I looked, put the mirror and said, "My God, what is this?" I could not even tell where the tear was ... I did not have the courage to put my hand to clean it, I felt discomfort.

I got scared to do some activity and, increase the pressure on the spot. Still after childbirth, I had urine loss ... especially in the early days, up to 3 days, sometimes I had to count the time I had drunk some liquid and go as soon as possible to the bathroom because if I took much time, I would feel the pee leaking. It was scary. (P17)

The pees were unbearable, because the pee passed and burned within the tear... and my biggest fear was the first shower I took in the hospital, because that's when I went to wash my parts, the vagina, the anus, and ... it was very swollen ... I felt my perineum down there ... I said: "Guys, this is not going to come back again ..." I was sure ... it was a pain ... I could not even rub it, I could not even wipe it to clean it straight.

"The postpartum is a very lonely period. It's so crazy, because so much is said about childbirth that you don 't have many concerns. The postpartum, it's different... I received a visit from the postpartum nurse practitioner. At the doctor we came back 15 days to see the stitches. In both visits, I think they try to soften too much, you know? I don 't know if they think that we are more sensitive... which is bad, because instead of coping nobody talks to you" (P19)

I always have in my head that some consequence would have ... it was not something that affected me ... no, I think I always focus on the baby there, what I need more than myself.... So, my concern was if I was gaining weight, if I was really breastfeeding right...I think it was something I was adapting and ended up writing. 


\section{DISCUSSION}

Our study has found that perineal trauma is not only a suturing process, but it consolidates the final phase of an existential transition that begins during antenatal care. More importantly, the women felt that the support of a humanized birth influence the suturing process; in fact, women were not connected with pain or bother or symptoms of guilt or unhappiness that could be generated by this diagnosis. This seems different from what we know from childbirths assisted in a traditional model, where the humanized features do not prevail; a mixed methods study has found that women who experienced psychological distress during current childbirth related to the suturing process expressed more concerns about future functioning and healing ${ }^{17}$. This information is important for feedback to the multidisciplinary team because perineal trauma may also cause the sensation of frustration and impotence on the health professionals that assist deliveries ${ }^{11}$.

Despite women have reported good assistance from the humanized birth model, they felt that perineal trauma should be more openly discussed during antenatal period. Thus, regardless of the birth care model, there is still a lack of information during this phase. Quality improvement projects to reduce the incidence of OASIS have incorporated as a key element the antenatal information to women; 18 this should become a reality since there are recommendations that pelvic floor trauma should be performance indicators of maternity services ${ }^{19}$.

Childbirth was a very dynamic process, similar to a phenomenological study by Hall et al.20 that found a balance between "keeping it together and falling apart". Women's reports deal with this paradoxical feeling of being happy to overcome the labor process and afraid of not "finishing it". Despite we did not specifically investigated tokophobia (fear of childbirth $)^{21}$, we believe this was not a confounding factor because in almost all reports women are very satisfied with the whole process, suggesting that the support from a multidisciplinary team gave them tools for self-empowerment.

Women during pregnancy seems to perform a crossing through fear towards childbirth. Woman develops confidence in herself, in others, and, through an act of "surrender", acquires strength through the process. After this crossing, some women may better adjust conditions to postpartum; on the other hand, they may experience suffering, the pain of rupture, the modification of a modality of existing as a woman, which extends and remains for individual time space.

Being nonfamiliar with the unfoldings of the pregnancy and childbirth experience creates fear. In fact, this is part of a bigger change, that involves a physical, emotional, cultural, and existential modification. In this context, physical trauma is almost a materialization of existential change. We call this unexpected finding of existential transition and is embodied in a change of identity. The nonrecognition of the perineal area leads automatically to an inquiry: "Who am I?". Gender issues and culturally established patterns of beauty and acceptance permeate this new identity.

All these changes were intensified or predetermined by the conflict - lack of preparation and physical and emotional support. Of course, each person is unique and behaves in the face of the unknown in a specific way; however, it was remarkable that the lack of preparation and the feeling of abandonment were present in the experiences marked by confusion, fear and dissatisfaction. This study also draws attention to public policies that not only prioritize normal childbirth, but also to support women throughout the entire process of preparation, not only for prenatal care and childbirth, but specifically for postpartum care.

Strengths of our study are the cohort of women that underwent a humanized birth, a care model that is centered on the respect and wishes of the patient; this sample also represents a deeper insight from patients that live in Brazil, a country that presents the highest cesarean rates in the world. Despite these statistics, if women are empowered with knowledge, they will know the benefits of a vaginal delivery. The limitations of this study are that women were, for the most part, educated, employed (and mainly, health professionals) and had private health insurance. We have also reported narratives from women after 6-12 months postpartum, which might have influenced by recall bias. However, there is some data showing that the birth narratives remain stable $^{22}$ and we believe this had a minor influence on their reports. We did not have severe perineal trauma in our sample, and these complications would certainly modify the reports of our study, despite our primary goal was to listen to women with perineal trauma, regardless of the severity. 


\section{CONCLUSION}

Most of women after humanized birth perceived perineal trauma as an existential transition. In this sense, dealing with the perineal lesion in the puerperium does not necessarily deals with the physical injury, but also with what caused it, the gestation, the birth and why not say the newborn and the multidisciplinary team itself. All the categories from antenatal, labor and postpartum are connected and present a strong bond. The alterity condition was most often associated with reports of good experiences or as an attenuating factor of negative experiences. In addition, it was in the alterity constituted with the newborn that postpartum women were potentially conditioned to an existential reconfiguration, through the attribution of "being a mother", re-signifying their existence. Perineal trauma should be more discussed during antenatal period so that we can overcome barriers, better cope with patients in the postpartum phase and help them cross this transition in a more humanized manner.

\section{REFERENCES}

1 - Oliveira LS, Brito LG, Quintana SM, Duarte G Marcolin AC. Perineal trauma after vaginal delivery in healthy pregnant women. Sao Paulo Med J 2014;132(4):2321-8.

2 - Peppe MV, Stefanello J, Infante BF, Kobayashi MT, Baraldi CO, Brito LG. Perineal trauma in a low-risk maternity with high prevalence of upright position during the second stage of labor. Rev Bras Ginecol Obstet 2018;40(7):379-383.

3 - Abedzadeh-Kalahroudi M, Talebian A, Sadat Z, Mesdaghinia $E$. Perineal trauma: incidence and its risk factors. J Obstet Gynaecol 2018;6:1-6.

4 - Fernando RJ, Sultan AH, Freeman RM, Williams AA, Adams EJ. Royal College of Obstetricians \& Gynaecologists. The management of third- and fourth-degree perineal tears green top guideline no. 29, June 2015.

5 - Rusavy Z, Karbanova J, Kalis V. Timing of episiotomy and outcome of a non-instrumental vaginal delivery. Acta Obstet Gynecol Scand 2016;95(2):190-6.

6 - Tunestveit JW, Baghestan E, Natvig GK, Eide GE, Nilsen ABV. Factors associated with obstetric anal sphincter injuries in midwife-led birth: a cross sectional study. Midwifery 2018;62:264-272.

7 - Cluett ER, Burns E, Cuthbert A. Immersion in water during labour and birth. Cochrane Database Syst Rev 2018;5:CD000111.

8 - Aquino CI, Guida M, Saccone G, Cruz Y, Vitagliano A, Zullo F, Berghella V. Perineal massage during labor: systematic review and meta-analysis of randomized controlled trials. J Matern Fetal Neonatal Med 2018;19:1-13.

9 - Aasheim V, Nilsen ABV, Reinar LM, Lukasse M. Perineal techniques during the second stage of labour for reducing perineal trauma. Cochrane Database Syst Rev 2017;6:CD006672.

10 - Sveinsdottir E, Gottfredsdottir H, Vernhardsdottir AS, Tryggvadottir GB, Geirsson RT. Effects of an intervention program for reducing severe perineal trauma during the second stage of labor. Birth 2018; doi: 10.1111/birt.12409.

11 - Edqvist $M$, Lindgren $H$, Lundgren I. Midwives'lived experience of a birth where the woman suffers and obstetric anal sphincter injury - a phenomenological study. BMC Pregnancy Childbirth 2014;14:258.

12 - Priddis H, Dahlen H, Schmied V. Women's experiences following severe perineal trauma: a meta-ethnographic synthesis. J Adv Nurs 2012;69(4):748-759.

13 - Crookall R, Fowler G, Wood C, Slade P. A systematic mixed studies review of women's experiences of perineal trauma sustained during childbirth. J Adv Nurs 2018 doi:10.1111/jan.13724.

14 - Wagner M. Fish can 't see water: the need to humanize birth. Int J Gynecol Obstet 2001;75:S25-S37.

15 - Tong A, Sainsbury P, Craig J. Consolidated criteria for reporting qualitative research (COREQ): a 32-tem checklist for interviews and focus groups. Int J Qual Health Care 2007;19(6):349-357.

16 - Gutland C. Husserlian phenomenology as a kind of introspection. Front Psychol 2018;9:896. doi:10.3389/ fpsyg. 2018.00896

17 - Briscoe L, Lavender T, O'Brien E, Campbell M, McGowan L. A mixed methods study to explore women and clinicians' response to pain associated with suturing second degree perineal tears and episiotomies [PRAISE]. Midwifery 2015;31(4):464-72.

18 - Bidwell P, Thakar R, Sevdalis N, Silverton L, Novis V, Hellyer A, Kelsey M, van der Meulen J, Gurol-Urganci I. A multi-centre quality improvement project to reduce the incidence of obstetric anal sphincter injury (OASI): study protocol. BMC Pregnancy Childbirth 2018;18(1):331.

19 - Dietz HP, Pardey J,Murray H. Pelvic floor and anal sphincter trauma should be key performance indicators of maternity services. Int Urogynecol J 2015;26(1):2932.

20 - Hall PJ, Foster JW, Yount KM, Jennings BM. Keeping it together and falling apart: women 's dynamic experience of birth. Midwifery 2018;58:130-6.

21 - Demsar K, Svetina M, Verdenik I, Tul N, Blickstein I, Globvenik Velikonja N. Tokophobia (fear of childbirth): prevalence and risk factors. J Perinatal Medicine 2017

22 - Simkin P. Just another day in a woman 's life? Women's long-term perception of their first birth experience. Birth 1991;18:203-210. 


\section{Funding}

Coordenacao de Aperfeicoamento de Ensino Superior (CAPES), code number 001

\section{Disclosure of interests}

None declared

\section{Ethical approval}

The Institutional Review Board from Hospital das Clínicas da Faculdade de Medicina de Ribeirão Preto has approved this study (CAAE 58847616.9.0000.5440)

Corresponding author:

Luiz Gustavo Oliveira Brito, MD, PhD

Igobrito@gmail.com

Editor:

Prof. Dr Felipe Villela Gomes

Received: feb 27, 2021

Approved: apr 28, 2021 